\title{
AVALIAÇÃO DA DISPONIBILIDADE DE FERRO DE FEIJÃO COMUM (Phaseolus vulgaris L.) EM COMPARAÇÃO COM CARNE BOVINA ${ }^{1}$
}

\author{
Neila Camargo de MOURA², Solange Guidolin CANNIATTI-BRAZACA ${ }^{3, *}$
}

\begin{abstract}
RESUMO
O presente trabalho avaliou a disponibilidade do ferro do feijão comum e os efeitos de suas interações com ácido ascórbico e cistina em comparação a disponibilidade deste metal em carne bovina. Para a determinação do teor de ferro e diálise de ferro in vitro, foram realizadas análises químicas nas amostras de carne bovina (C), feijão comum (F), feijão comum com ácido ascórbico (FA), feijão comum com cistina (FCI) e feijão comum com ácido ascórbico e cistina (FACI). Em F foram determinados taninos, ácido fítico e ácido oxálico. Em $\mathrm{F}$ foi encontrado $0,065 \mathrm{~g}$ de tanino/100 g; 8,03 mg de ácido fítico/g e 7,12 mg de ácido oxálico/g. A quantidade de ferro variou de $9,64 \mathrm{mg} / 100 \mathrm{~g}$ a $10,37 \mathrm{mg} / 100 \mathrm{~g}$. A amostra FCI e FA apresentaram os menores teores de ferro. A quantidade de ferro encontrada na amostra C foi de $10,37 \mathrm{mg} / 100 \mathrm{~g}$. A porcentagem de ferro dialisável variou de $17,33 \%$ a $24,31 \%$. As amostras de carne bovina apresentaram a maior porcentagem de ferro dialisável, seguida por FACI. A menor porcentagem de ferro dialisável foi observada nas amostras F e FCI. Portanto, pode-se concluir que a adição simultânea de ácido ascórbico e cistina, tornou o ferro presente no feijão mais biodisponível, equiparando-o ao da carne bovina.

Palavras-chave: biodisponibilidade, ferro, ácido ascórbico, cisteína, antinutricionais
\end{abstract}

\section{SUMMARY}

EVLUATION OF IRON AVAILABILTY OF THE COMMON BEAN IN COMPARSON WITH BOVINE MEAT.

The present work evaluated iron availability of the common bean and the effects of its interactions with ascorbic acid and cystine in iron availability and compare the results with iron availability of the bovine meat. The determination of iron quantity and iron dialysis in vitro has been done by analysing the samples of bovine meat (M), common bean (B), common bean with ascorbic acid (BA), common bean with cystine (BCY) and common bean with ascorbic acid and cystine (BACY). In B, tannins, phytic acid and oxalic acid were determined. In the B sample, $0.065 \mathrm{~g}$ of tannins $/ 100 \mathrm{~g} ; 8.03 \mathrm{mg}$ of phytic acid/g and $7.12 \mathrm{mg}$ of oxalic acid/g were found. The iron quantity varied from $9.64 \mathrm{mg} / 100 \mathrm{~g}$ to $10.37 \mathrm{mg} / 100 \mathrm{~g}$. The BCY and BA samples presented the smallest iron quantity. The iron quantity found in the sample $\mathrm{M}$ was $10.37 \mathrm{mg} / 100 \mathrm{~g}$. The percentage of iron availability varied from $17.33 \%$ to $24.31 \%$. The M sample presented the largest percentage of iron availability, followed by BACY. The smallest percentage of iron availability was observed in B and BCY samples. Therefore, in conclusion, the iron bean became more bioavailability because of the simultaneous addition of ascorbic acid and cystine compared with the iron of bovine meat.

Keywords: bioavailability, iron, ascorbic acid, cystine, antinutritionals.

\section{1 - INTRODUÇÃO}

Estima-se que quase $40 \%$ da população mundial apresentam carência de ferro ou níveis baixos de hemoglobina, estabelecendo uma situação de risco que inclui indivíduos tanto dos estratos sociais mais privilegiados como dos mais carentes, especialmente o grupo materno-infantil: lactentes, pré-escolares, escolares, gestantes e nutrizes. Como pode existir deficiência de ferro sem a presença de anemia, a ocorrência de carência de ferro na população

$\overline{\text { Recebido para publicação em 23/07/2004 Aceito para publicação em }}$ 25/04/2006 (001382)

${ }^{2}$ Aluna do curso de graduação em Nutrição da Universidade Metodista de Piracicaba e estagiária no Departamento de Agroindústria, Alimentos e Nutrição da Escola Superior de Agricultura "Luiz de Queiroz" da Universidade de São Paulo

3 Professora-doutora do Departamento de Agroindústria, Alimentos e Nutrição da Escola Superior de Agricultura "Luiz de Queiroz" da Universidade de São Paulo

*A quem a correspondência deve ser enviada apresenta uma magnitude ainda maior do que a prevalência da anemia ferropriva [2, 9]. A carência desse nutriente prejudica a nutrição e a saúde, o desenvolvimento físico e o aprendizado [14].

BIANCHI, SILVA \& DUTRA DE OLIVEIRA [5] ressaltam que, embora a anemia seja um dos maiores problemas mundiais de saúde pública, paradoxalmente, a média de ferro total presente na dieta de diversas regióes encontra-se acima das recomendações diárias necessárias para suprir o uso metabólico normal desse mineral. A anemia é decorrente da baixa biodisponibilidade do ferro nos alimentos, principalmente os de origem vegetal.

Existem duas formas químicas do ferro nos alimentos: o ferro heme e não-heme. O primeiro encontra-se na estrutura do anel porfirina, ligado à hemoglobina e mioglobina, representando cerca de $40 \%$ do ferro do tecido animal. Sua absorção é elevada e não é influenciada pelos fatores antinutricionais. As formas inorgânicas ou ferro não-heme estão presentes tanto em tecidos animais como em todos 
os vegetais que contêm ferro; porém, são de baixa biodisponibilidade $[8,9,16,21]$.

A absorção do ferro se dá do seguinte modo: o ferro absorvido no trato gastrointestinal se liga a uma glicoproteína: a transferrina. Ligado a esta proteína, o ferro circula pelo organismo. Na superfície das células, o ferro liga-se a receptores específicos. O complexo transferrina-ferro ligado a receptores penetra na célula. A transferrina libera o ferro deixando a outra parte (apotransferrina) voltar à superfície celular, retornando em seguida à circulação, continuando então o seu ciclo [3, 9].

O ácido ascórbico, quando ingerido juntamente com o ferro não-heme, potencializa sua absorção, mantendo-o na forma de quelato solúvel no intestino delgado [1]. O ácido ascórbico e a carne ou tecido animal são os dois maiores promotores dietéticos, conhecidos, da biodisponibilidade de ferro. O ácido ascórbico, como agente redutor, mantém o ferro dos alimentos no estado ferroso, que é mais solúvel. Também, forma quelato ferro-ascorbato, que se mantém solúvel mesmo com o aumento do $\mathrm{pH}$ no intestino delgado proximal [25]. O ferro da alimentação contido nas frutas e vegetais, que são ricos em ácido ascórbico, normalmente, é $15 \%$ disponível. A absorção do ferro aumenta de 3,7\% para $10,4 \%$ em refeições com pão, ovo e chá quando se adiciona de 40 a $50 \mathrm{mg}$ de ácido ascórbico [4, 5].

As carnes podem aumentam de duas a quatro vezes a absorção do ferro não-heme, este fato ocorre pela presença de altas quantidades de aminoácidos sulfurados em conjunto com a ausência de fatores que inibam a absorção do ferro. Entretanto, as proteínas contidas no queijo e leite, reduzem significativamente a absorção de ferro devido a altas concentrações do cálcio. No ovo a baixa disponibilidade ocorre devido às proteínas ligadoras de ferro, como a fosvitina [16]. O mecanismo exato pelo qual os tecidos facilitam a absorção do ferro não-heme é ainda desconhecido, mas tem sido proposto que aminoácidos livres na luz intestinal, como a histidina, lisina e cistina, aumentam a absorção da espécie férrica, por formarem quelatos solúveis com o ferro [4]; foi sugerido que os peptídeos, liberados durante a digestão proteolítica pela pepsina no estômago, podem melhorar a solubilidade do ferro inorgânico. Esse aumento da absorção pode ser atribuído à propriedade dos aminoácidos, especialmente os sulfurados, como a cistina, a qual se liga ao ferro inorgânico, mantendo-o solúvel e disponível para a absorção [21].

Alguns fatores intraluminais afetam negativamente a quantidade de ferro disponível para absorção. Entre esses pode-se citar os fatores antinutricionais, tais como o ácido oxálico, o ácido fítico e polifenóis (taninos por exemplo), que podem formar precipitados, quelatos insolúveis ou macromoléculas que diminuem a absorção do ferro [3, 4, 5].

O consumo de proteína animal, especialmente a carne bovina, é freqüentemente associado aos malefícios à saú- de humana. A carne bovina magra, similarmente à carne branca das aves (sem pele) e o lombo suíno, são fontes importantes de proteína e devem fazer parte de uma dieta balanceada com os nutrientes dos demais grupos de alimentos [21, 25].

O feijão constitui a base alimentar da maioria dos brasileiros, é uma fonte de proteína de baixo valor biológico, porém apresenta elevado teor de lisina, carboidratos complexos, além da presença de vitaminas do complexo $\mathrm{B}$ e de ferro. Com relação à proteína, o feijão apresenta deficiência de aminoácidos sulfurados metionina e cistina, ambos essenciais na alimentação [2, 16].

O feijão pode e dever compor os cardápios, sobretudo os econômicos, porém deve ser complementado com alimentos com teor adequado de aminoácidos essenciais, que são as carnes, ovos ou outras combinações vegetais [25, 28]. A biodisponibilidade do ferro nos alimentos depende da forma química em que o elemento se encontra e das possíveis interações com outros constituintes dos alimentos [1]. CANNIATTI-BRAZACA \& SILVA [6] observaram que o tipo de leguminosa, bem como a presença de alimentos promotores, influenciaram na disponibilidade do ferro. De acordo com os autores, o grão-de-bico e o feijão comum apresentaram as melhores disponibilidades de ferro.

O objetivo deste trabalho foi avaliar a disponibilidade do ferro do feijão comum (Phaseolus vulgaris L.) variedade carioca e suas interações com ácido ascórbico e cistina e comparar com a disponibilidade do ferro de carne bovina. Além disso, propôs verificar a quantidade de antinutricionais presentes no feijão e averiguar sua interferência na biodisponibilidade do ferro.

\section{2 - MATERIAL E MÉTODOS}

\section{1 - Amostras}

Foram utilizados grãos de feijão comum (Phaseolus vulgaris), variedade Carioca, recém-colhidos e doados pelo Departamento de Produção Vegetal da Escola Superior de Agricultura Luiz de Queiroz da Universidade de São Paulo. O músculo bovino fresco picado em cubos de aproximadamente $1 \mathrm{~cm}$, foi adquirido no comércio local. Utilizou-se também ácido L-Ascórbico e L-Cistina, ambos da marca Synth de grau analítico (99 e 98\% de pureza, respectivamente).

\section{2 - Preparo das amostras}

\subsection{1 - Feijão}

O feijão foi lavado, deixado sob maceração por $12 \mathrm{~h} \mathrm{em}$ água deionizada na proporção de 1:3 (feijão:água) sendo a água descartada e adicionada na proporção 1:2 (feijão: água) para posterior cozimento em autoclave por $10 \mathrm{~min}$ a $121^{\circ} \mathrm{C}$, conforme metodologia descrita por MOLINA, FUENTE \& BRESSANI [20]. 


\subsection{2 - Músculo bovino}

O músculo bovino foi cozido em panela de inox aberta, em fogo médio, por $30 \mathrm{~min}$, utilizando $434 \mathrm{~g}$ de músculo e $500 \mathrm{~mL}$ de água deionizada, que foi acrescentada aos poucos durante a cocção da carne.

\subsection{3 - Preparo das amostras para análise}

Para as análises de diálise de ferro in vitro, as amostras dos diferentes tratamentos foram homogeneizadas e armazenadas em congelador a $-18^{\circ} \mathrm{C}$. Para a realização dessa análise, as amostras não foram desidratadas.

Já, para as demais análises, as amostras foram desidratadas em estufa a $55^{\circ} \mathrm{C}$ a $60^{\circ} \mathrm{C}$, moídas em moinhos de facas da marca Marconi modelo especial 60 ciclos, peneiradas a 30 mesh, acondicionadas em embalagem plástica de polietileno e mantidas refrigeradas à aproximadamente $11^{\circ} \mathrm{C}$ para análises posteriores. Todas as determinações foram realizadas em triplicata.

\subsection{4 - Tratamentos}

As amostras de carne foram analisadas isoladamente e as amostras de feijão foram analisadas isoladamente e também com o acréscimo de ácido ascórbico e cistina. Deste modo, foram testados os seguintes tratamentos:

T1 - Carne bovina

T2 - Feijão comum

T3 - Feijão comum:ácido ascórbico, na proporção 200 g: $100 \mathrm{mg}$

T4 - Feijão comum:cistina, 200 g: $5 \mathrm{mg}$

T5 - Feijão comum: ácido ascórbico:cistina, 200 g: 100 mg: $5 \mathrm{mg}$

\section{3 - Fatores antinutricionais}

A determinação de fatores antinutricionais foi realizada somente no tratamento 2 , na amostra de feijão.

\subsection{1 - Taninos}

Os taninos foram analisados segundo a metodologia descrita por PRICE, HAGERMAN \& BUTLER [23], através da extração de $0,2 \mathrm{~g}$ de amostra com $10 \mathrm{~mL}$ de metanol em agitação por 20 min e centrifugação a 15.232 g por 10 min. Em seguida foi realizada a reação colorimétrica, com solução de vanilina a $1 \%$ em metanol e $8 \%$ de $\mathrm{HCl}$ em metanol na proporção de $1: 1$ e com incubação a $30^{\circ} \mathrm{C}$ por $20 \mathrm{~min}$. Então, a partir de $1 \mathrm{~mL}$ de extrato e $5 \mathrm{~mL}$ de solução de vanilina foi realizada a leitura a $500 \mathrm{~nm}$ em espectrofotômetro Beckman modelo DU 640, obtendo-se assim a concentração de taninos a partir de uma curva padrão de catequina, sendo os resultados expressos em $\mathrm{mg} / \mathrm{g}$.

\subsection{2 - Ácido fítico}

$\mathrm{O}$ teor de ácido fítico nas amostras foi determinado segundo o método descrito por GRYNSPAN \& CHERYAN [13]. A Figura 1 mostra como a análise foi realizada.

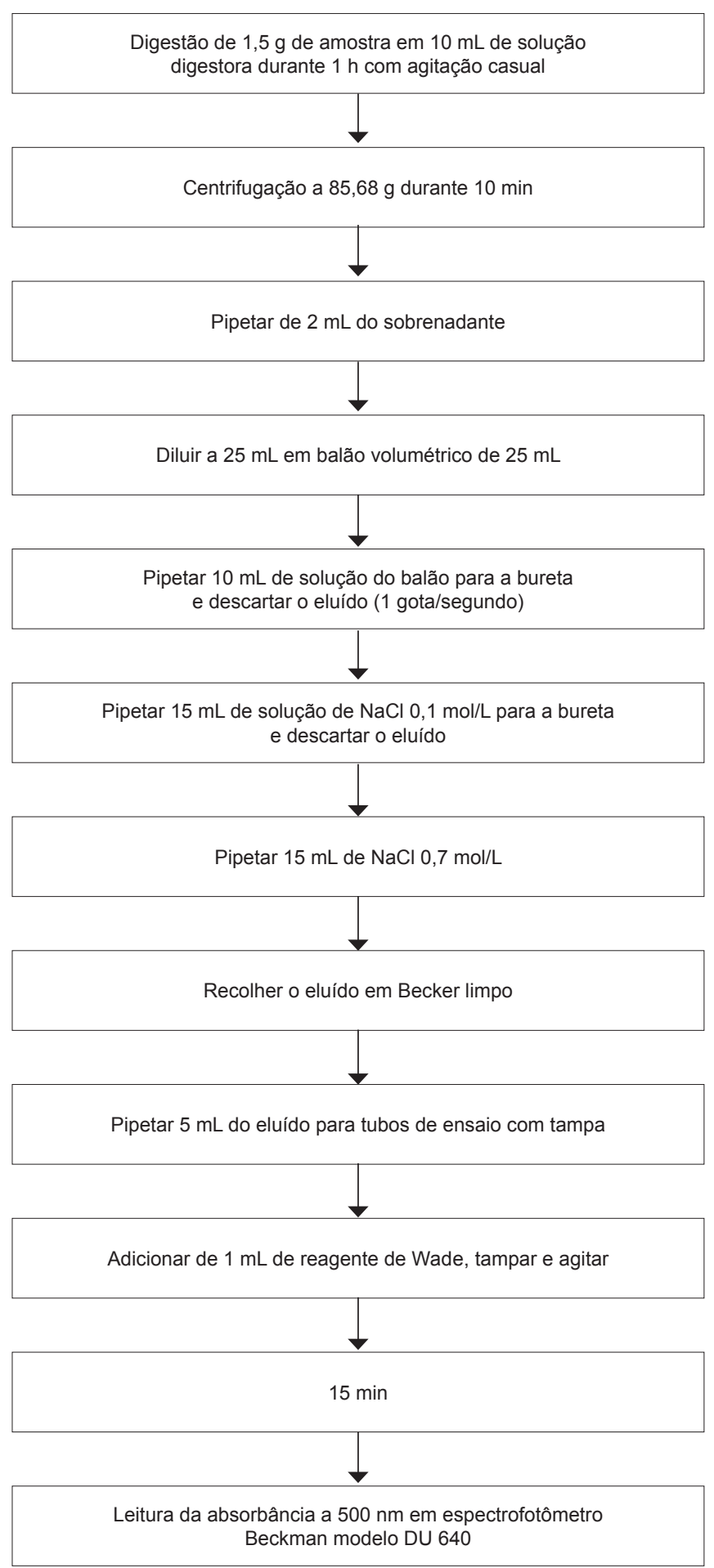

FIGURA 1 - Seqüencia de análise de ácido fítico

O teor de ácido fítico foi obtido a partir da construção de curva padrão. Os resultados foram expressos em mg de ácido fítico/g de amostra.

\subsection{3 - Ácido oxálico}

O ácido oxálico foi determinado pelo método de MOIR [19]. A Figura 2 mostra como a análise foi realizada. 


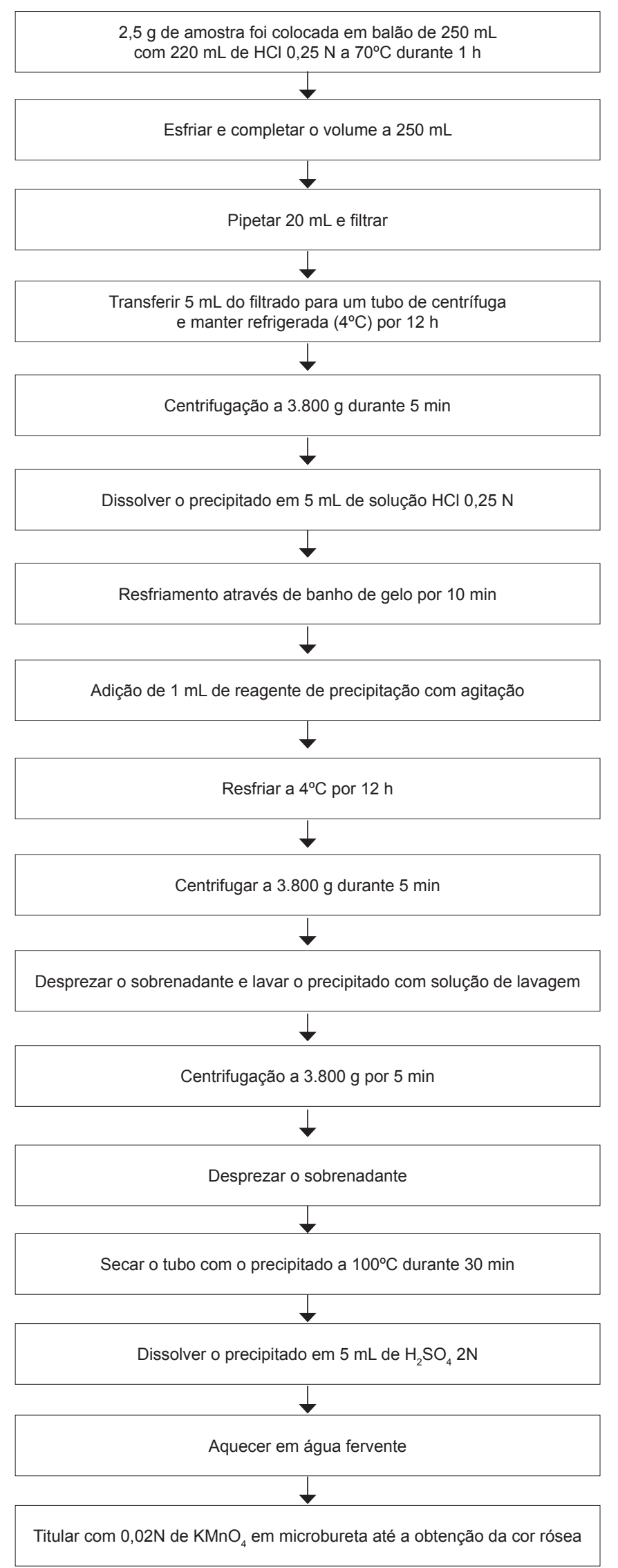

FIGURA 2 - Seqüencia de análise de ácido oxálico
Para a obtenção do conteúdo de ácido oxálico, multiplicou-se o volume gasto (em $\mathrm{mL}$ ) por 1,80:

$$
\text { Volume }(\mathrm{mL}) \times 1,80=\% \text { de ácido oxálico }
$$

\section{4 - Minerais}

Os minerais foram determinados pelo método de SARRUGE \& HAAG [26], sendo utilizado o ácido nítrico para a digestão nitro-perclórica das amostras a $50^{\circ} \mathrm{C}$ por 10 a $15 \mathrm{~min}$, a $100^{\circ} \mathrm{C}$ até digerir todo o material e atingir a temperatura de $150^{\circ} \mathrm{C}$, sendo reduzida a solução pela metade, foi acrescentado $1 \mathrm{~mL}$ de ácido perclórico e a temperatura foi elevada até $250^{\circ} \mathrm{C}$ gradativamente. Após resfriamento e diluição do material com água desmineralizada, foi realizada a leitura em espectrofotômetro de absorção atômica.

\section{5 - Diálise de ferro in vitro}

A análise da diálise de ferro foi realizada segundo método proposto por LUTEN, CREWS \& FLYNN [15]. As Figuras 3, 4 e 5 demonstram como a análise foi realizada.

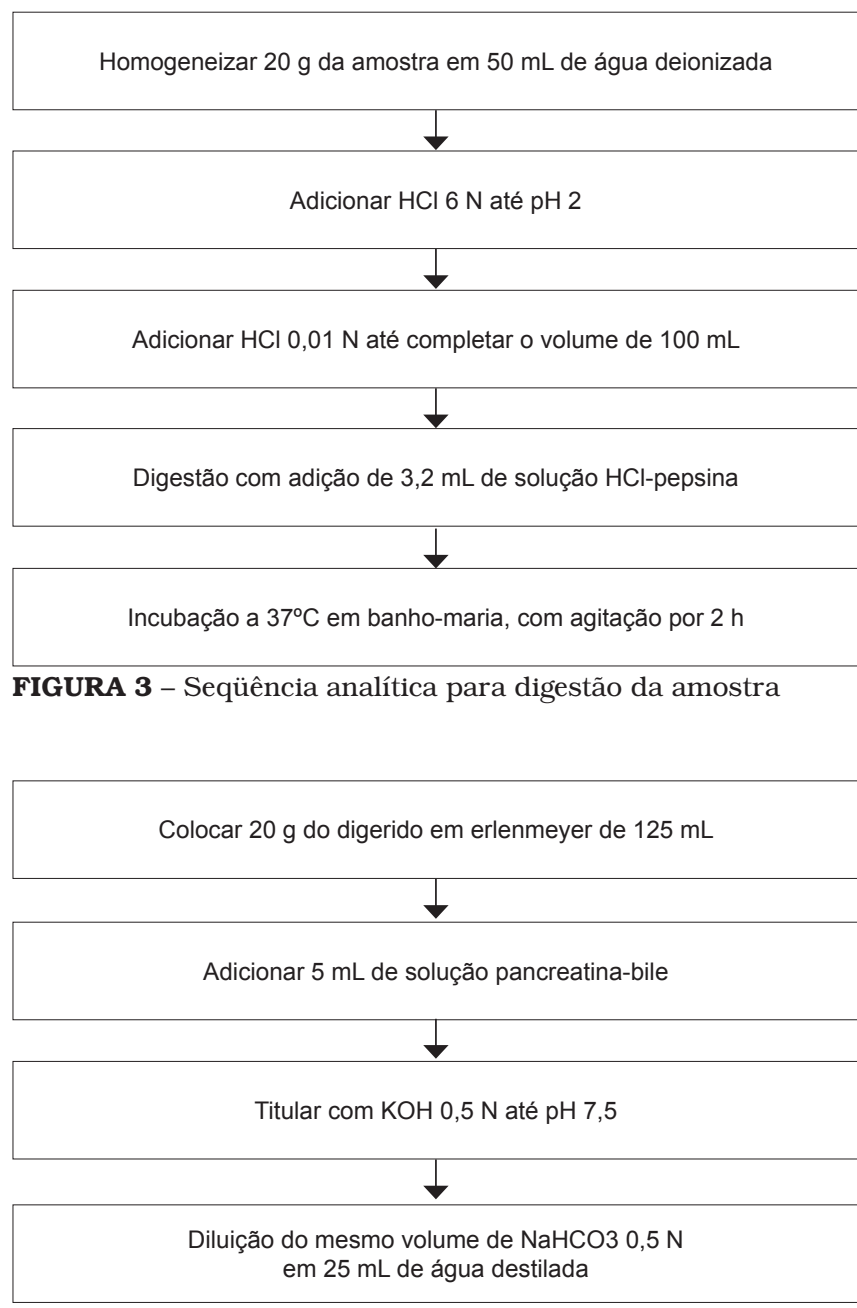

FIGURA 4 - Seqüência analítica para acidez titulável 


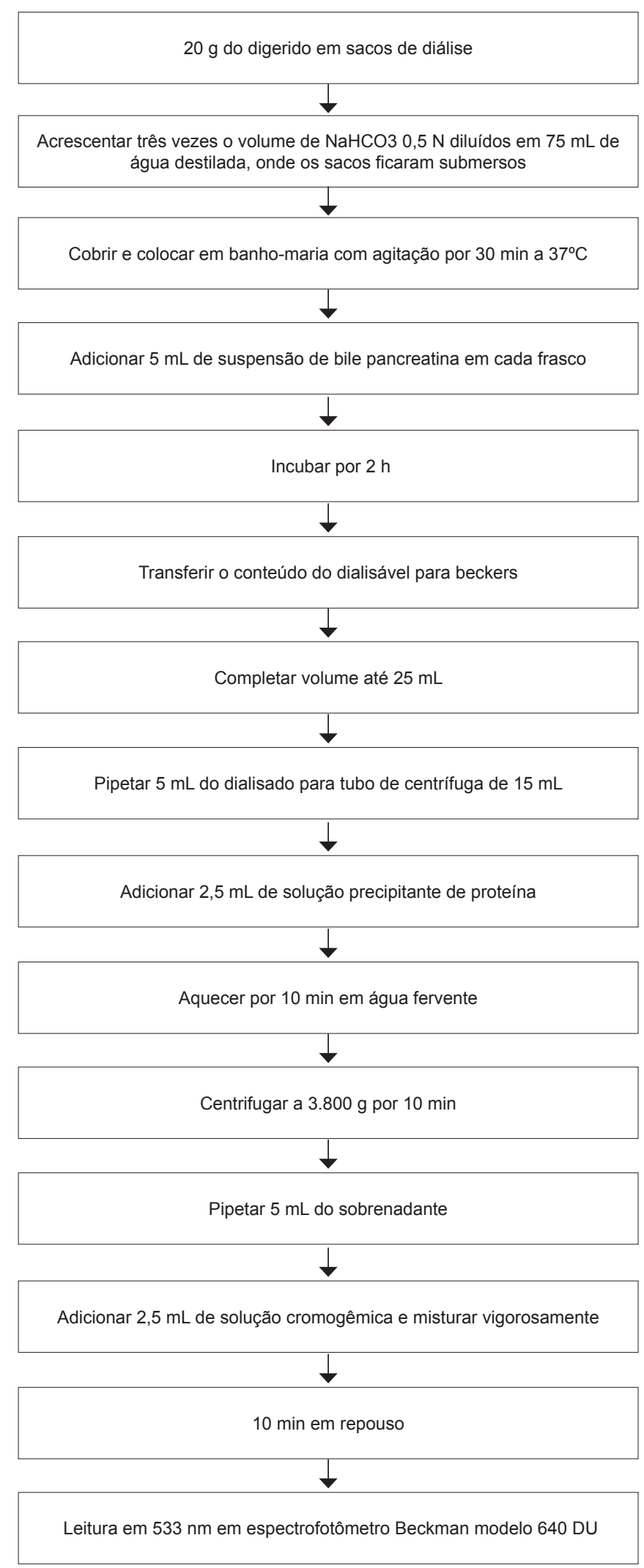

FIGURA 5 - Seqüência analítica para diálise

A quantidade de ferro dialisado foi obtida através de curva padrão com cloreto de ferro.

\section{6 - Análise estatística}

O delineamento experimental empregado foi inteiramente ao acaso, com três repetições por tratamento, totalizando 15 amostras. Os resultados foram submetidos à análise de variância, com teste $\mathrm{F}$. Quando significativo no teste $\mathrm{F}$ a 5\% de probabilidade, foi aplicado teste de Tukey, sendo utilizado para os cálculos o software SAS [27].

\section{3 - RESULTADOS E DISCUSSÃO}

Os antinutricionais foram avaliados somente na amostra de feijão Carioca, visto que a carne não apresenta estes fatores (Tabela 1).

TABELA 1 - Composição de antinutricionais (taninos, ácido fítico e ácido oxálico) presente em feijão comum variedade carioca (base seca)

\begin{tabular}{lc}
\hline Antinutricionais & Feijão Carioca \\
\hline Taninos (\%) & $0,065^{1} \pm 0,00$ \\
Ácido Fítico $(\mathrm{mg} / \mathrm{g})$ & $8,03 \pm 0,16$ \\
Ácido Oxálico $(\mathrm{mg} / \mathrm{g})$ & $7,12 \pm 0,00$ \\
\hline
\end{tabular}

${ }^{1}$ Média \pm desvio padrão

O teor de taninos encontrada, em feijão comum, por MARTINI [18] foi de 0,18\%. WEDER et al. [29] encontraram, para o grão cru de feijão, variação de 0,57 a $0,73 \%$ de taninos. CANNIATTI-BRAZACA \& SILVA [6] encontraram $0,034 \%$ de taninos no feijão. OLIVEIRA, QUEIROZ \& HELBING [22] observaram que somente o processo de cozimento ocasionou redução do conteúdo de tanino, e que o melhor tratamento para a remoção de tanino foi a maceração, seguida da cocção sem a água de maceração, chegando a $88 \%$ a redução no teor de taninos. Como foi utilizado o processo de maceração e descarte da água, ocasionou a diminuição dos teores de taninos na amostra, como pode ser observado na Tabela 1.

A quantidade de ácido fítico encontrada por MARTINI [18] foi de 10,66 mg/g. CANNIATTI-BRAZACA \& SILVA [6] encontraram $6,38 \mathrm{mg} / \mathrm{g}$ para o feijão Carioca.

Já GUZMÁN-MALDONADO, ACOSTA-GALLEGO \& PAREDES-LÓPEZ [12], verificaram para o feijão cozido, variação entre 10,0 a $18,3 \mathrm{mg} / \mathrm{g}$ para espécies de feijões selvagens e 7,3 a 10,8 mg/g para os feijões comuns. Portanto, os valores encontrados (Tabela 1) para ácido fítico estão dentro dos valores apresentados por outros autores.

GERMANO [11] avaliou a disponibilidade de ferro e ácido oxálico na presença de $\beta$-caroteno em combinações de alimentos fontes de ferro (espinafre, feijão e ovo) e de alimentos fonte de $\beta$-caroteno (cenoura, abóbora e couve). O teor de ácido oxálico encontrado variou de 0,14 a 0,27\%, sendo que a mistura com espinafre apresentou maiores concentrações. Porém, o teor de ácido fítico variou de 0,00 a 1,03 mg/g, sendo que as maiores concentrações predominaram nas amostras com feijão. Isso revela que o feijão apresentou índices mais elevados para o ácido fítico que para o ácido oxálico, como também ocorreu na presente pesquisa (Tabela 1). 
TABELA 2 - Teor de ferro presente no feijão comum variedade Carioca, carne bovina e misturas de feijão com ácido ascórbico, cistina e sua combinação (base seca)

\begin{tabular}{lc}
\hline Amostras & Teor de ferro $\mathbf{~ m g / g}$ \\
\hline Carne covina & $0,1037^{1} \pm 0,0022^{2}$ a \\
Feijão Carioca cozido & $0,1013 \pm 0,0009^{\text {a }}$ \\
Feijão Carioca cozido com ácido ascórbico & $0,0993 \pm 0,0019$ a, b \\
Feijão Carioca cozido com cistina & $0,0964 \pm 0,0025^{\text {b }}$ \\
Feijão Carioca cozido com & $0,1013 \pm 0,0002^{\text {a }}$ \\
ácido ascórbico e cistina & \\
${ }^{1}$ Média \pm desvio padrão & \\
${ }^{2}$ Letras diferentes na vertical indicam diferença significativa $(\mathrm{p} \leq 0,05)$
\end{tabular}

A quantidade de ferro encontrada (Tabela 2) coincide com FRANCO [10] que apresentou o teor de 0,1023 mg de ferro/100 g de carne bovina.MALDONADO \& SAMMÁN [17] verificaram em 10 variedades de feijão cru variação de 0,0891 a 0,7600 mg/g de ferro. SAMMÁn et al. [25] encontraram concentração de ferro em torno de 0,0533 a $0,2002 \mathrm{mg} / \mathrm{g}$. CANNIATTI-BRAZACA \& SILVA [6] encontraram $0,0931 \mathrm{~m} / \mathrm{g}$ de ferro em feijão Carioca cozido expressos na base seca. MARTINI [18] encontrou 0,0587 mg de ferro/g de alimento. Esses dados apontam similaridades com os resultados encontrados no presente estudo (Tabela 2).

A Tabela 3 apresenta os valores de diálise de ferro para carne bovina, o feijão e feijão com os promotores de absorção.

TABELA 3 - Porcentagem da diálise de ferro do feijão comum variedade carioca, carne bovina e misturas de feijão com ácido ascórbico, cistina e sua combinação (matéria fresca)

\begin{tabular}{lc}
\hline Amostras & \% de ferro dialisado \\
\hline Carne bovina & $24,3165^{1} \pm 0,5691^{2 \mathrm{a}}$ \\
Feijão Carioca cozido & $17,3351 \pm 0,1038^{\mathrm{b}}$ \\
Feijão Carioca cozido com ácido ascórbico & $18,3401 \pm 0,4732^{\mathrm{b}}$ \\
Feijão Carioca cozido com cistina & $17,7233 \pm 0,3320^{\mathrm{b}}$ \\
Feijão Carioca cozido com & $23,9186 \pm 1,1342^{\mathrm{a}}$ \\
ácido ascórbico e cistina & \\
${ }^{1}$ Média \pm Desvio padrão & \\
${ }^{2}$ Letras diferentes na vertical indicam diferença significativa $(\mathrm{p}<0,05)$
\end{tabular}

Considerando os alimentos de forma isolada, a carne bovina apresentou a maior porcentagem de ferro dialisável. Isto já era esperado, pelo fato deste alimento conter em sua estrutura ferro na forma heme e aminoácidos que propiciam sua absorção. O feijão cozido, acrescido de ácido ascórbico e cistina, se igualou à carne, mostrando efeito aditivo quando há presença dessas duas substâncias. As menores porcentagens de ferro dialisável foram observadas nas amostras de feijão carioca cozido e feijão carioca cozido acrescido apenas de cistina. Quando foram simultaneamente adicionados ao feijão o ácido ascórbico e a cistina, elevou-se a porcentagem do ferro dialisável, igualando-se ao da carne bovina, que contêm aminoácidos sulfurados. Porém pelos resultados encontrados, somente o ácido ascórbico não foi suficiente para promover a disponibilidade do ferro do feijão no mesmo nível do que a da carne e somente a cistina não apresentou efeito de melhora na absorção do ferro não-heme do feijão a nível semelhante ao encontrado na carne.

REEVES et al. [24] avaliaram ratos machos, deficientes em cobre, alimentados com uma dieta contendo cobre, ferro, manganês e cistina e uma dieta com cobre, ferro, manganês e metionina. Nos ratos deficientes, após a ingestão da dieta contendo cistina, passaram a apresentar maiores concentrações de hemoglobina no sangue do que os ratos alimentados com a dieta contendo metionina.

Em um outro estudo, COSTA, TERTO \& SANTOS [7] avaliaram a prevalência de deficiência de vitamina $\mathrm{C}$ em 104 crianças de 2 a 6 anos de creches municipais de João Pessoa (PB). Para 72 crianças com níveis baixos de vitamina $\mathrm{C}$ foi oferecido durante 35 dias, $150 \mathrm{~mL}$ de suco de acerola. Após esse período, ocorreu um aumento significativo na concentração média de hemoglobina, evidenciando a relação entre ácido ascórbico e ferro.

A aplicabilidade desse estudo, em nível doméstico, dá-se através da combinação, numa mesma refeição, entre alimentos ricos em vitamina $\mathrm{C}$ e alimentos que contenham cistina, como os cereais. Por exemplo, $50 \mathrm{~g}$ de feijão Carioca acompanhados de $100 \mathrm{~g}$ de arroz e de 100 g de salada de pimentão verde cru, ofertam quantidades iguais ou superiores de cistina e ácido ascórbico (84 mg/ $100 \mathrm{mg}$, respectivamente) utilizadas na pesquisa. Porém é apropriado lembrar que outras substâncias presentes nesses alimentos interferirão na biodiponibilidade desses nutrientes.

\section{4 - CONCLUSÕES}

A quantidade de antinutricional encontrada exerceu efeito inibitório sobre a disponibilidade de ferro da amostra de feijão, porém com acréscimo simultâneo da cistina e do ácido ascórbico melhorou a absorção do ferro do feijão, igualando-o à absorção do ferro da carne bovina.

\section{5 - REFERÊNCIAS BIBLIOGRÁFICAS}

[1] ANTUNES, P.L.; SGARBIERI, V.C. Fatores antinutricionais, toxicidade e valor nutricional do feijão comum (Phaseolus vulgaris, L.). Agros, v. 15, n. 1, p. 39-62. 1980.

[2] BATISTA-FILHO, M.; FERREIRA, L.O.C. Prevenção e tratamento da anemia nutricional ferropriva: novos enfoques e perpectivas. Cadernos de Saúde Pública, v. 12, n. 3, p. 411-415, 1996.

[3] BEARD, J.L; DAWSON, H.; PIÑERO, D.J. Iron metabolism: a comprehensive review. Nutrition Reviews, v. 54, n. 0, p. 295-317, 1996.

[4] BIANCHI, M.L.P. Biodisponibilidade de ferro em produtos industrializados de soja. São Paulo, 1988, 187 p. Dissertação (doutorado em Ciência e Tecnologia de Alimentos). Universidade de São Paulo, USP.

[5] BIANCHI, M.L.P.; SILVA, H.C.; DUTRA DE OLIVEIRA, J.E. Considerações sobre a biodisponibilidade do ferro dos alimentos. Archivos Latinoamericanos de Nutrición, v. 42, n. 2, p. 94-100, 1992. 
[6] CANNIATTI-BRAZACA, S.G.; SILVA, F.C. Avaliação do aproveitamento do ferro de leguminosas por dálise in vitro. In: Congresso Nacional da Sociedade Brasileira de Alimentação e Nutrição, 20, São Paulo, 1999. Resumos. São Paulo: Sociedade Brasileira de Alimentação e Nutrição, 1999, 258 p.

[7] COSTA, M.J.C.; TERTO, A.L.Q.; SANTOS, L.M.P. Efeito da suplementação com acerola nos níveis sanguíneos de vitamina $\mathrm{C}$ e de hemoglobina em crianças pré-escolares. Revista de Nutrição, v. 14, n. 1, p. 13-20, jan.-abr. 2001

[8] DE ANGELIS, R.C.; CTENAS, M.L.B. Biodisponibilidade de ferro na alimentação infantil. In: S.1.: Nestlé - Serviço de Informação Científica, (Temas de Pediatria). 53 p., 1993

[9] FAIRBANKS, V.F. Iron in medicine and nutrition. In: SHILLS, M.E.; OLSON, J.A.; SHIKE, M. Modern nutrition in health and disease. $8^{\text {th }} \mathrm{ed}$. Philadelphia: Lea \& Febiger, 1994, p.185-213.

[10] FRANCO, G. Tabela de composição química dos alimentos, 9 ${ }^{\mathrm{a}}$ ed. São Paulo: Atheneu, 1992.

[11] GERMANO, R.M.A. Disponibilidade de ferro na presença do $\beta$-caroteno e o efeito dos interferentes em combinaçóes de alimentos. Piracicaba, 2002. Dissertação (Mestrado em Ciência e Tecnologia de Alimentos), Departamento de Agroindústria, Alimentos e Nutrição, Escola Superior de Agricultura Luiz de Queiroz (Esalq/USP).

[12] GUZMÁN-MALDONADO, S.H; ACOSTA-GALLEGO, J; PAREDES- LOPEZ, O. Protein and mineral content of a novel collection of wild and weedy common bean (Phaseolus Vulgaris $L$ ). Journal of the Science of Food and Agriculture, v. 80, n. 13, p. 1.874-1.881, Oct. 2000.

[13] GRYNSPAN, F; CHERYAN, M. Phytate-calcium interaction with soy protein. Journal of the American Oil Chemists Society, v. 66, n. 1, p. 93-97, 1989.

[14] HALLBERG, L.; BRUNE, M.; ERLANDSSON, M. Calcium: effect of different amounts on nonheme-and heme-iron absorption in humanas. American Journal of Clinical Nutrition, v. 53, n. 1, p. 112-119, 1991.

[15] LUTEN, J.; CREWS, H.; FLYNN, A. Interlaboratory trial of the determination of the in vitro iron dialysability from food. Journal of Science and Food Agriculture, v. 72 , n. 4, p. 415-424, 1996.

[16] LYNCH, S.R. Interacion of iron witch other nutrients. Nutrition Reviews, v. 55, n. 4, p. 102-110, 1997.

[17] MALDONADO, S.; SAMMÁN, N. Composición química y contenido de minerals de leguminosas y cereales producidos in el noroeste argentino. Archivos Latinoamericanos de Nutrición, v. 50, n. 2, p. 195-199, 2000.

[18] MARTINI, F.C.C. Comparação entre a disponibilidade de ferro na presença de vitamina $A$ e beta-caroteno em alimentos e medicamentos. Piracicaba, 2002. Dissertação (Mestrado em Ciência e Tecnologia de Alimentos), Departamento de Agroindústria, Alimentos e Nutrição, Escola Superior de Agricultura Luiz de Queiroz (Esalq/USP).

[19] MOIR, K.W. Determination of oxalic acid in plant Queensland. Journal Agricultural Science, v. 10, n. 1, p. 1-3, 1953.

[20] MOLINA, M.R.; FUENTE, G.; BRESSANI, R. Interrelationships between storage, soaking time, cooking time, nutritive value and other characteristics of the black bean (Phaseolus vulgaris). Journal of Food Science, v. 40, p. 587-591, 1975.

[21] O ferro na alimentação humana. Dieta e Saúde, v. 3, n. 1, p. 1, 1994.

[22] OLIVEIRA, A.C.; QUEIROZ, K.S.; HELBING, E. O processamento doméstico do feijão comum ocasionou uma redução nos fatores antinutricionais fitatos, taninos, no teor de amido e em fatores de flatulência rafinose, estaquiose e verbascose. Archivos Latinoamericanos de Nutrición, v. 51, n. 3, p. 276-283, 2001.

[23] PRICE, M.L.; HAGERMAN, A.E.; BUTLER, L.G. Tannin content of cowpeas, chickpeas, pigeonpeas and mung beans. Journal Agricultural and Food Chemistry, v. 28 , n. 2 , p. $459-461,1980$.

[24] REEVES, P.G.; RALSTON, N.V.C.; IDSO, J.P.; LUKASKI, H.C. Contrasting and cooperative effects of cooper and iron deficiencies in male rats fed different concentrations manganese and different sources of sulfur amino acids in an AIN-93G- based diet. Journal of Nutrition, v. 134, n. 2, p. 416-425, Feb. 2004.

[25] SAMMÁN, N.; MALDONADO, S.; ALFARO, M.E.; FARFÁN, N.; GUTIERREZ, J. Composition of different bean varieties (Phaseolus vulgaris) of northwestern Argentina (region NOA): cultivation zone influence. Journal Agricultural and Food Chemistry, v. 47, n. 7, p. 2.685-2.689, 1999.

[26] SARRUGE, J.R.; HAAG, H.P. Análises químicas em plantas. Piracicaba: USP/Esalq, 1974.

[27] STATISTICAL ANALYSIS SYSTEM INSTITUTE. Sas/Qc Software: usage and referente. $2^{\text {nd }}$ ed. Cary, 1996, 2 v.

[28] VALLE, E.R. Carne bovina: alimento nobre indispensável. http:://www.embrapa.br. Acesso em: 3 abr. 2003.

[29] WEDER, J.K.P.; TELEK, L.; VOZÁRI-HAMPE, M.; SAINI,H.S. Antinutritional factors in anasazi and other pinto beans(Phaseolus vulgaris). Plant Foods for Human Nutrition, v. 51, p. 85-98, 1997.

\section{6 - AGRADECIMENTOS}

Ao Departamento de Solos e Nutrição de Plantas Esalq/ USP pelo auxílio na análise de ferro. 